University of Nebraska - Lincoln

DigitalCommons@University of Nebraska - Lincoln

2009

\title{
The challenge of leading on unstable ground: Triggers that activate social identity faultlines
}

\author{
Donna Chrobot-Mason \\ University of Cincinnati, donna.chrobot-mason@uc.edu \\ Marian N. Ruderman \\ Center for Creative Leadership, ruderman@ccl.org \\ Todd J. Weber \\ University of Nebraska-Lincoln, todd.weber@gmail.com \\ Chris Ernst \\ Center for Creative Leadership, ernstc@ccl.org
}

Follow this and additional works at: https://digitalcommons.unl.edu/leadershipfacpub

Part of the Management Sciences and Quantitative Methods Commons

Chrobot-Mason, Donna; Ruderman, Marian N.; Weber, Todd J.; and Ernst, Chris, "The challenge of leading on unstable ground: Triggers that activate social identity faultlines" (2009). Leadership Institute Faculty Publications. 1.

https://digitalcommons.unl.edu/leadershipfacpub/1

This Article is brought to you for free and open access by the Leadership Institute at DigitalCommons@University of Nebraska - Lincoln. It has been accepted for inclusion in Leadership Institute Faculty Publications by an authorized administrator of DigitalCommons@University of Nebraska - Lincoln. 


\title{
The challenge of leading on unstable ground: Triggers that activate social identity faultlines
}

\author{
Donna Chrobot-Mason, Marian N. Ruderman, \\ Todd J. Weber and Chris Ernst
}

\begin{abstract}
Today's leaders face unprecedented challenges in attempting to manage interactions between social identity group members with a history of tension in society at large. Research on faultlines suggests that social identity groups often polarize in response to events that make social identity salient, resulting in negative work outcomes. The current research extends the faultlines literature by examining precipitating events (triggers) that activate a faultline. Qualitative interview data were collected from two samples of employees working in multiple countries to identify events that had resulted in social identity conflicts. In the first study (35 events), an exploratory approach yielded a typology of five types of triggers: differential treatment, different values, assimilation, insult or humiliating action, and simple contact. A second qualitative study (99 events) involved a more geographically varied sample. Research findings are discussed in terms of implications for the faultlines literature and for practicing leaders.
\end{abstract}

Keywords: conflict, diversity, intergroup, leadership, management, organizational psychology

Leaders in the global economy face the significant challenge of leading on the unstable ground often found between social identity groups with a history of tension or distrust in society at large (Chrobot-Mason et al., 2007). 
Globalization, rapidly advancing technology, changing demographics, and shifting government structures have brought together groups of workers with past histories of hostilities, disputes, and intergroup anxiety (Stephan $\&$ Stephan, 1985). A disagreement in the workplace that on the surface may appear to be a minor misunderstanding between two individuals can escalate if groups polarize and attribute the cause of the conflict to social identity tensions.

Recently, the concept of faultlines has emerged in the literature to explain the phenomena of social identity differences and conflict in the workplace (Lau \& Murnighan, 1998). The authors define faultlines as "hypothetical dividing lines that may split a group into subgroups based on one or more attributes" (Lau \& Murnighan, 1998: 328). Research on faultlines has shown that the pattern of group member attributes can result in hidden dividing lines within the organization along which groups are likely to subdivide (Lau \& Murnighan, 2005). Events that make social identity particularly salient have the potential to cause groups to polarize along these faultlines (Simon \& Klandermans, 2001; Wetherell, 1987), and the resulting polarization may negatively influence work.

To date, there has been very little research, if any, conducted to examine what types of events, behaviors, or circumstances in the workplace activate faultlines and lead to group polarization. Without such an understanding, it is difficult for leaders to know when and how to respond to events that have the potential to result in social identity conflict in the workplace. Preliminary research suggests leaders often fail to act in situations where social identity-based conflict occurs, despite there being a wide expectation that they address the issue (Gentry et al., 2007). While reasons for inaction may vary, effective leadership solutions are likely to require a more in-depth understanding of the activation of faultlines than most leaders' possess. To fully evaluate the context in which they lead and engage in effective leadership strategies, it is critical that leaders understand social identity group anxiety and conflict.

Therefore, in the present study, we seek to extend the faultlines literature by developing a typology of faultline triggers based on field data from a variety of cultural contexts. In the sections that follow, we review literature on social identity theory, inter-group anxiety, and faultlines to illustrate how social identity conflicts emerge in the workplace. We present the findings of two studies that resulted in the development of a typology of triggers, and finish with a discussion of strengths/limitations, future research opportunities, and implications for leaders. 


\section{Social identity theory}

One of the fundamental aspects of social identity theory is that an individual has both a personal and social identity (Pelham \& Hetts, 1999). An individual derives their self-concept in part from membership in a social group, along with the psychosocial value and emotional significance associated with membership in that group (Turner \& Giles, 1981). Individuals classify themselves and others into categories or groups through a cognitive process that provides individuals with a systematic means of defining others as well as helping the individual to define him or herself within the social environment (Ashforth \& Mael, 1989). Any individual has many different social identities that vary in terms of salience and importance (Crisp \& Hewstone, 2007).

Social identity researchers have added a great deal to our understanding of identity salience and importance, both of which are complex psychological and cognitive processes. Social identity becomes particularly salient when it is associated with minority status, when social groups have meaning within a particular context or organization, and when identity is threatened as a result of negative stereotypes or treatment directed toward one's group (Steele et al., 2002). Identity salience invokes a cognitive process in which individuals interpret events based at least in part on the strength of their identification with that social identity group, often resulting in a strong emotional response to the fate of the group (Ellemers et al., 1999; Haslam \& Ellemers, 2006).

Fundamental to these cognitive processes is a comparison with those who are not part of the social group, and the associated desire for one's ingroup to have a positive evaluation relative to the out-group (Tajfel, 1979). Not surprisingly, the desire for each group to remain both distinctive and superior to others can lead to conflict. This is especially true in cases where social identities are based on less permeable characteristics, including such attributes as race/ethnicity (Jackson \& Neville, 1998; Linnehan et al., 2006; Verkuyten, 2004), gender (Hogg et al., 2006), religion (Weaver \& Agle, 2002), and immigrant status (Cheryan \& Monin, 2005) that, in many parts of the world, have been historically associated with significant divisions or strife within society.

Because a social identity is collectively experienced, it is fundamentally a contextually defined social psychological construct. For example, a friendly joke shared between two individuals from different social identity groups may take on a dramatically different meaning if it is interpreted as an affront to one member's social identity group. Steele et al. (2002) describe such affronts as social identity threats. These are subtle cues suggesting that one may be vulnerable or treated poorly simply owing to social 
identity group membership. The interpretation of and reaction to specific events can easily become a group level social identity threat in contexts where there is a history of tension between social identity groups. Simon and Klandermans (2001) suggest that we may distinguish social identity conflicts from interpersonal disagreements based on the nature of the causal attributions made by the disputants and by the amplification of the event to a larger collective. Whereas an interpersonal disagreement may be associated with individual differences, social identity conflicts occur when groups attribute causality to social identity characteristics and intergroup history. To begin to understand the broader social psychological context of social identity conflicts and the challenge leaders face when bridging group differences, it is important to examine the history of intergroup tensions and its ability to polarize groups along such faultlines in organizational settings. Therefore, we provide a review of research on inter-group anxiety and conflict, followed by a review of the faultlines literature.

\section{Inter-group anxiety and conflict}

Conflict or tension between identity groups in organizations and the society as a whole is not simply a result of present day conflict. Many social identity groups have an extensive history of conflict that can have a powerful influence on the way interactions between groups are perceived today. The degree to which there are current tensions as a result of historical conflict is referred to as intergroup anxiety (Stephan \& Stephan, 1985). This anxiety is thought to be the result of prior intergroup relations, prior intergroup cognitions, and situational factors that characterize the intergroup interaction (e.g. type of interdependence, group composition, relative status). Groups with higher levels of intergroup anxiety anticipate negative consequences or unfavorable comparisons resulting from contact with the other group (Fisher, 2000; Stephan \& Stephan, 1985).

The existence of high levels of intergroup anxiety may result in feelings of social identity threat, avoidance of intergroup interaction, heightened emotional responses to out-group members, and information processing that is biased toward the in-group, each making it more likely that identity-based conflict will occur (Stephan \& Stephan, 1985). According to social identity theory (Tajfel, 1979), when a lower status group believes themselves to be treated unfairly, they are inclined to identify with their group and engage as a collective in an attempt to address the inequity. High levels of intergroup anxiety may make it difficult for members of different social identity groups to work together, particularly in the aftermath of major conflicts in society 
(e.g. the detonation of a bomb targeting a specific social identity group). Even relatively low levels of intergroup anxiety can make it difficult for a leader to bridge differences and manage social identity conflict effectively.

Leaders are faced with a considerable challenge when attempting to lead across social identity groups with a history of intergroup anxiety or conflict. Because organizational leaders are often members of the dominant social group and/or have attained status and power as a result of their position, they may have difficulty both recognizing and responding to triggers effectively. The social identity theory of leadership speaks to some of these issues. Hogg's (2001) social identity theory emphasizes the characteristics of the leader as a group member, and the ability of the leader to speak to followers as group members. Leadership effectiveness, the theory argues, may be understood as the extent to which the leader is prototypical of the group, and engages in valued group-oriented behavior. This argument extends the earlier work of Turner (1987), who suggested that the group member who is most likely to exercise leadership is the individual who is most representative of the shared social identity of the group. Haslam (2001) proposes that a particular group member will be perceived as prototypical to the extent that the person is similar to members of his/ her own group (i.e. represents the ideals and essence of the group) and different from members of other groups.

The need for a leader to be both similar and different from groups makes it very difficult for leaders to bridge social identity group differences and suggests that leaders play a critical role in either contributing to or mitigating conflict. Intergroup conflict is also an important issue for leaders to consider because intergroup conflict can negatively impact leadership outcomes. Drath et al. (2008) offer a refined theory of leadership suggesting that there are three essential outcomes that leaders strive for: direction, alignment, and commitment. Leaders accomplish direction when there is agreement among the collective members of the group regarding the aim, mission, vision or goal of the collective's shared work. Alignment is achieved when knowledge and work in the collective is coordinated and organized. And finally, commitment is accomplished when members are willing to subsume their efforts within the collective efforts (Drath et al., 2008). These three outcomes, direction, alignment, and commitment, are according to this theory, the essence of leadership success.

However, successful leadership in these areas becomes considerably more difficult when identity subgroups become salient and polarize within the collective. The present study helps to identify different types of triggers that activate faultlines, making direction, alignment, and commitment difficult to achieve. We argue that it is critical that leaders, often members of 
the dominant group, develop a greater awareness of the context and history of social identity conflicts that emerge in the workplace and understand the types of events that may trigger a conflict within their teams. In the next section, we review the faultlines literature and explain how the present study contributes to this growing field of inquiry.

\section{Fault lines in organizations}

Lau and Murnighan (1998) proposed a construct called faultines, which may help explain the phenomena of identity salience, intergroup anxiety, and subsequent conflict in the workplace. They argued that we must begin to view diversity in work teams as more complex and consider not single attributes, but rather the compositional dynamics of multiple demographic attributes that can potentially subdivide groups and create conflict within organizations. They suggest that faultlines in groups are analogous to geological faults in the Earth's crust; they are always present, they create various levels of friction as boundaries rub together, pull apart, grind, and collide; and yet they may go unnoticed without the presence of external forces (Lau \& Murnighan, 1998).

However, when an external force is present, such as an event that serves to polarize or highlight differences based on gender, race, religion, etc., faultlines may become activated. Although the activation of faultlines may result in a variety of outcomes, the increased salience of subgroup identities makes power struggles and conflict among subgroups likely to ensue. Stronger faultlines (when attributes align themselves in such a way that there are distinct homogeneous subgroups) provide an even greater opportunity for work groups to polarize, revealing the importance of attributes and magnifying the effects of external forces.

Since the publication of Lau and Murnighan's (1998) seminal paper, there has been an emerging interest in this topic as demonstrated by the research conducted in this area in recent years. Several researchers have examined the negative impact of faultlines on workplace outcomes. Molleman (2005) found that faultlines due to diversity in ability and personality impaired team functioning. Li and Hambrick (2005) empirically demonstrated that faultline size was negatively associated with emotional conflict, which subsequently had a negative relationship with work team performance (as two factions grew more distinct in their demographic characteristics, emotional conflict increased and work performance ultimately declined as a result). Rico et al. (2007) demonstrated that strong-faultline groups (highly homogeneous work groups) made lower quality decisions 
and had lower social integration (i.e. team member satisfaction and commitment) than weak-faultline groups.

Taken together, the faultlines, inter-group anxiety, and social identity literature help to explain how and why social identity groups may engage in conflict within the work context. Social identity theory and research on intergroup anxiety provides the basis for understanding the importance of social identity to our self-concept, the conditions under which identity becomes salient, and why individuals and groups often feel their own identity is threatened by others (see Haslam \& Ellemers, 2005 for a review). The faultlines concept builds upon these ideas and applies them to work groups in an organizational setting by illustrating how subgroups form along demographic or social identity lines and examining the negative consequences for crossgroup interactions that result when faultlines are activated.

Our research further contributes to this work by attempting to illuminate what activates faultlines and causes social identity groups to polarize at work. By extending the existing literature to include a more thorough examination of triggers, we seek to help leaders better understand the unstable ground they often find themselves walking on when leading across social identity groups in conflict. In the next section, we define the concept of triggers and attempt to illustrate the antecedents and consequences of triggers as they emerge and escalate in the workplace.

\section{Defining triggers}

A recent manuscript by Chrobot-Mason et al. (2007) describes the process by which social identity conflicts emerge and escalate in the following manner. In an increasingly diverse workplace, members of groups with a history of conflict or tension often find themselves required to work together. Intergroup anxiety resulting from previous conflicts among groups may serve as a primer for future conflicts that emerge in the work context (Stephan \& Stephan, 1985). Social identity group membership can be one type of faultline that exists within the organization, and can become activated when external forces or events make group membership distinctions salient, often resulting in group conflict. This knowledge of history has the potential to activate stereotypes about different groups (Shelton et al., 2006; Steele et al., 2002).

For example, an event associated with everyday work life occurs acting as a cue that one group may be devalued versus another group or discriminated against based on social identity. According to Steele et al. (2002), such an event makes people vigilant about sensing whether social identity is a factor in the behavior of others. This realization comes from the con- 
text of the larger society. Thus, a particular event in the workplace may or may not evoke identity threat. It depends on whether the event is significant and meaningful within the larger societal context. We call such an event a trigger and define it as an event involving two or more people from different social identity groups that ignites a replication of societal-based identity threat in an organization.

When an event activates faultlines, the anxiety, tension, or intergroup conflict originating in society has the potential to "erupt" (just as the underlying pressure found beneath the geologic faults in the Earth's crust) and negatively impact interactions among employees within the organization. Triggers act as a signal that the environment may be psychologically threatening to particular social identity groups (Murphy et al., 2007). Steele et al. (2002) point out that even small features of the environment have great power when it comes to signaling a message about the status of a particular social identity group. In groups with strong faultlines, the possibility of a small event being perceived as threatening may be strong because the salience of group membership is high. In the present study, we address a gap in the current literature by examining triggers that activate faultines in the workplace. We attempt to answer the following research questions:

RQ1: What events make social identity salient and activate faultlines that cause groups to polarize at work?

RQ2: What type of events are most frequently observed across a multinational sample?

\section{Methods and results}

To date, the majority of research on social identity conflict and faultlines has been based on student samples and artificially created work groups. This allows for important experimental manipulations of group composition and examinations of controlled group interactions, but is unlikely to capture the range of complex and dynamic relationships often associated with faultines. To understand what primes faultlines, research must track faultlines as they emerge naturally in context. This requires research methodologies that can obtain detailed descriptions of events that have occurred in the workplace. Our study attempts to extend the social identity and faultlines literature in the following ways. First, we have gathered qualitative field data from two studies involving a wide variety of organizational and cultural contexts using an inductive approach and relying on thematic analysis (Boyatzis, 1998) to understand the activation of faultlines. Gathering observational data from 
the field was essential given our effort to capture the range of triggers that naturally occur. Second, rich qualitative data allows us to better illuminate both the context and the dynamics involved in the activation of faultlines what causes cracks to emerge and how groups polarize as a result.

We intentionally analyzed interviews for the current manuscript involving work groups where intergroup anxiety was moderate to high (due to a historical backdrop of negative interactions between subgroups in society). We focused our attention on faultlines involving social identity groups such as nationality, religion, race, gender and sexual orientation, because faults along these lines in society are often aligned with inequalities and therefore charged with emotion. Faultlines based on social identity group membership are also more likely to lead to conflict and ultimately, to impact leadership outcomes (e.g. direction, alignment, and commitment). Many researchers have argued that social identity conflicts are difficult to resolve and often intractable (Putnam \& Wondolleck, 2003; Rothman, 1997) because they involve disputes over the intrinsic value of the social group with which individuals strongly identify, and consequently the individual's own value is at stake (Cavey, 2000; Hicks, 2001). Therefore, by design, we gathered data in which strong faultlines were activated by triggering events, thus setting the stage for conflict in the workplace.

We conducted two studies to examine what types of triggers activate faultlines. The first study took an exploratory approach seeking to develop a general typology of triggers in an organizational context. Our intention was to be able to elaborate on the faultlines model by examining the organization- based events that activate identity threat in the workplace. This study yielded a rich description of the triggering events, and we developed a typology of triggers based on our analysis. We conducted a second qualitative study to deepen the initial analysis and determine if a more geographically varied sample would yield new or different triggers. Although the typology developed in Study 1 could have been tested in Study 2 by creating a standardized instrument, we felt it was premature to do so given the small size of the original sample and the single perspective on an event. Therefore, we again used a qualitative approach in Study 2 to elaborate on the typology and seek new categories of triggering events.

\section{Study I}

\section{Sample}

Interviews were conducted with a total of 50 individuals located in 11 different countries: South Africa, US, Israel, Saudi Arabia, Singapore, Zimbabwe, Mozambique, Zambia, Bali, Germany, and the UK. Because our inter- 
est for this first study was in understanding the phenomenon rather than widespread generalizability, we took a purposive approach (Stone, 1978) to identifying the sample. First, we identified interviewers versed in the practice of leadership development in multicultural settings from among the research team's associates and international colleagues. Second, we asked interviewers to identify a sample of people who were likely to have experienced or witnessed social identity conflicts in the workplace. Because of the sensitivity of the topic, we did not ask the interviewers to collect demographic data on the interviewees. The sole requirement was experience working in a setting likely to be characterized by social identity conflict. The men and women interviewed held a variety of occupations in corporations, social service organizations, hospitals, and schools serving a multicultural constituency. They were managers, teachers, nurses, social workers, firefighters, professionals, and educational administrators and employed at all levels of the organizational hierarchy. We interviewed individuals who held formal leadership positions within the organization as well as individuals with no formal leadership authority, since we believe that leadership, as well as social identity conflict, can occur at any organizational level. This approach allowed us to understand the challenge of social identity conflict from a variety of different perspectives.

\section{Data collection}

Each interview was conducted using a semi-structured interview protocol. Interviewers were trained to first establish rapport and then to use a critical incident approach (Butterfield et al., 2005; Flanagan, 1954) to identify events that had resulted in social identity conflicts. Interviewers were provided with a guide that included both practical suggestions for conducting an effective interview as well as recommendations for probing and soliciting the critical information needed to address our research questions. Interviewers were given sample probing questions to elicit information about the external socio-historical-cultural context (e.g. Does this story reflect a societal level issue of group conflict? What are the historical or social issues involved?), the history of the identity groups involved (e.g. Who was involved in the conflict? What were the main causes of feelings of tension between groups?), and the circumstances leading to and resulting from the intergroup conflict (e.g. How did the conflict start? How was it resolved? If it was not resolved, why not?).

Interviewees were given background on the study and the questions in advance to ensure they felt prepared. Interviewers began the interview by first explaining the concept of social identity as the part of a person's identity that comes from belonging to a particular group. It was distinguished 
from personal identity and examples of social identity groups were provided. Thus it was made clear to the interviewees that the type of conflict we were interested in exploring stemmed from social identity tensions and anxiety in the larger social-historical context, rather than conflict stemming from a temporarily polarizing event in the organization (e.g. the sales and marketing teams are in conflict about an issue involving occupancy of a particular suite of offices).

Interviewers began with a series of questions to elicit information about the various social identity groups represented in the organization and how well group members interact. Following this, the interviewer continued to the main part of the interview seeking information about a specific event in which members of the organization were in conflict with each other due to social identity differences. The central question in the protocol was:

I would like you to think about a time or an event in which you became strongly aware of the fact that people from different social identity groups were working together, and they fell short of their best - the groups were at odds with one another. There may have been misunderstandings and there may have even been outright tension and conflict. Tell me a story about this time. What happened? How could you tell the groups were not working well together?

Once the interviewee had described a specific event, the interviewer probed with additional questions (see above for examples) to fully understand the circumstances leading up to the event, the details of the event, and the aftermath of the event. Interviewees were assured the interviews were confidential and each gave permission for the interviews to be recorded. All interviews were conducted in private, and each interviewee was informed prior to the interview that no one in their employing organization would receive any feedback from the interview. After completing their set of interviews, each interviewer was asked to write a memo summarizing key themes across their interviews. At the request of the interviewers in Israel, South Africa, and Saudi Arabia, interviewee names were not made available to the larger research team; only the interviewers knew their actual identity.

\section{Data analysis}

All but one of the interviews were transcribed verbatim. The remaining interview was summarized by the interviewer. When necessary, interviews were translated into English. Two of the authors independently read all of 
the interviews and summary memos in order to identify themes explaining similarities and differences in the event stories. We then met to discuss our perceptions and realized that we did see patterns in the triggering events in the stories. We reread all the transcripts and summarized the events that contained triggering incidents. From the 50 interviews, 35 stories involving specific events were identified. To qualify, an event had to meet several conditions. First, the event had to happen between two or more workers from different social identity groups that mirrored a social identity conflict in the larger society. The event could not be something purely personal. The parties involved felt some type of threat to identity that was observed by the interviewee. Second, the event had to have a negative outcome in the production of work. Finally, the event needed to provide sufficient details about the incident for both analysts to agree on what happened. Thus, vague descriptions were eliminated; we retained only cases involving rich information.

Following the inductive approach described by Strauss and Corbin (1990), we noted labels, words, or phrases describing each trigger succinctly. We grouped these summaries and labels into more abstract categories and described each category as a theme. Following Boyatzis (1998) we then turned the themes into codes containing a name, definition, indicators of the code, examples, and exclusions. Then each analyst independently returned to the data, rereading each interview and coding it. The two analysts then met to discuss the codes and reconciled any discrepancies through discussion. The codebook was revised to reflect changes in our thinking. Once the data set was coded, a third analyst was enlisted to independently code the data using the codebook so as to provide an indicator of agreement. Table 1 contains the codes and the level of agreement on the presence of each code in the data between the first rating assigned by the two analysts who generated the codes and this additional analyst.

\section{Results}

Overall, analysis of the triggering events support research on conflict escalation described by Northrup (1989). Anxiety from society at large was apparent in the workplace. Certain events triggered an eruption of social-identity based tension in the workplace. Feelings of identity tension "spilled over" into the organization. Employees reported feeling the possibility of harm, being left out, being ostracized, or not getting their "fair share." This tension had a negative impact on the work, typically in the form of a stoppage or slowdown of group functioning. Typically situations escalated as the number of workers involved in the dispute and the intensity of the issue increased. Sometimes the tension dissipated on its own. 
Table I. Triggers of social identity conflicts

\begin{tabular}{lrr}
\hline Theme definitions & $\begin{array}{r}\text { Percentage } \\
\text { of sample } \\
\text { demonstrating } \\
\text { theme }\end{array}$ & $\begin{array}{r}\text { Percentage } \\
\text { of rater } \\
\text { agreement }\end{array}$ \\
\hline
\end{tabular}

Differential treatment: Group polarization can occur when groups receive unequal opportunities in the workplace or receive unequal treatment. The dominant and non-dominant group members may see the treatment differently with the dominant group members perceiving differences in treatment as a demonstration of loyalty and non-dominant groups perceiving it as favoritism. The treatment may have to do with distribution of resources such as promotions, pay, opportunities or praise or disciplinary actions.

Different values: Decidedly different beliefs or values can trigger a social identity conflict. There is a clash of fundamental beliefs regarding what is right and wrong or normal and abnormal. The values may be religious, moral or political.Values can also trigger a conflict when a particular job responsibility may violate deeply held values or beliefs.

Assimilation:These triggers occur when the majority group expects that others will act just like them. It represents an intolerance of cultural, religious, or gender differences. There is an expectation on the part of the dominant groups that the non-dominant groups will assimilate and blend into the dominant culture.

Insult or humiliating action: Comments or behaviors that devalue one group relative to another. An offensive comment, insult, slur, or humiliation of someone from another identity group can make identity highly salient. The insultee clearly feels hurt by the incident. Others take sides.

Simple contact:When intergroup anxiety is high, simple contact between these groups can be polarizing. Simply bringing these group members together can trigger polarization and conflict.

In other cases, members of the organization had to deal with the feelings of threat or harm requiring intervention to de-escalate the situation. Many formal leaders were taken by surprise. This was especially true of members of the dominant group in society because they were inexperienced in dealing with identity-based threats. They were accustomed to being on the privileged side of faultlines and were unaware that the view from the other side was different until an event disrupted work. To improve our under- 
standing of the events triggering social identity conflicts, we systematically described and coded these events. This process resulted in the identification of five themes.

Differential treatment accounted for 29 percent of the incidents. Differential treatment occurs when dominant and non-dominant groups see their treatment differently. Group polarization occurs when resources or punishments are perceived as being differentially distributed. The perception of threat is created by feeling undervalued owing to this differential distribution of rewards and punishments. This category represents the classic example of social identity threat - in-group favoritism and out-group derogation. In our organization-based data there were examples of harsher punishment being given to a member of an out-group, higher performance ratings awarded to in-groups, and more promotions going to in-groups than to out-groups. Consider the following example from Saudi Arabia:

... So let's say you have a senior executive that's a member of a certain tribe. He's expected by that entire tribe to take care of the tribe. This supersedes the company. So, what are some of the results of that? Well, he'll hire as many from the tribe as possible, let's say. Or he'll try promoting some of them faster than others and if he has a certain last name ... You can actually go into our telephone book by tribe and figure out which group is headed by whom.

In this organization, the preference for members of certain tribes triggered an event from those non-members who felt well-qualified and felt they were unfairly treated.

Dominant and non-dominant group members interpret differential treatment very differently. Dominant group members may perceive differential treatment as a demonstration of loyalty to their own kind and nondominant group members may see such actions as favoritism. In addition to promotions, pay, disciplinary actions, and allocation of developmental opportunities served as the foci of the differential treatment. All of these distribution decisions have the potential to activate employee feelings of being undervalued and underappreciated.

Different values was the next most common category of social identity conflicts. These occurred in 26 percent of the sample. These events occurred when social identity groups had decidedly different beliefs or values. What is seen as "right" by one group was seen as "wrong" by another. The values may be religious, moral or political. For example, in one social service organization, a worker was asked to accompany a client to an abortion. He thought this was wrong because it violated his religious beliefs. Others in the organization felt it was part of his job and he should just do it. Another 
example had to do with people whose religious beliefs conveyed that homosexuality is wrong needing to collaborate with gay co-workers. In one case, a work team split on this issue, with two members refusing to work with two other team members. The interviewee was a team member, who reported:

That's a precipitating event (the outing of a gay colleague), then you have the born again Christians saying, "I don't recognize that construct-I don't recognize that construct of being gay." The bible doesn't say it's so ... you have that whole "my religion tells me to do this, but the law is telling me to do this and our company subscribes to ' $x$ ' and I don't believe it." So, that becomes a real values dilemma for people. A fundamental values dilemma.

In this situation identity groups felt threatened because their fundamental sense of right and wrong was called into question by another identity group and the organization itself suffered because a great deal of energy was devoted to this issue and members refused to work with one another.

Assimilation events accounted for 23 percent of the sample. These triggers occur when the majority group expects that others will act just like them. There is an expectation that non-dominant groups will assimilate and melt into the dominant culture. These stories were told from the perspective of either a dominant group member or non-dominant group member. When a dominant group member told the story it was about the nondominant group being different. For example, an American executive at an American company told us that he received complaints that his European hires "smelled bad" and that many employees would like them to follow American norms for hygiene. The hygiene issue precipitated a situation in which it was hard to get Americans and Europeans working together in a hot warehouse to cooperate.

Members of the dominant group tend not to like it when co-workers of other cultures express their distinctiveness. They feel threatened by expressions of a different identity and worry about losing their dominance. For example, in Israel, a native Israeli instructor got annoyed when a group of Russian students complained about her rule that they could not play Russian music in the classroom or comfortably speak in Russian. The instructor for the class, a native speaker of Hebrew told us:

I tried to explain to them that it doesn't feel good when they talk in Russian in front of me and I don't understand and they know it, and that it is very impolite to exclude a person out of a conversation like that, just because he doesn't understand the language. 
When members of a non-dominant group tell assimilation stories it has to do with either not being able to express their own culture or being asked to celebrate the culture of another group. In a number of different contexts there were examples about holiday celebrations privileging certain groups over others.

Insults or humiliating actions comprised 17 percent of the triggering events. These comments or behaviors devalued one group relative to another. Offensive comments, insults or humiliating acts that were attributed to identity polarized groups quickly. These comments or actions are blatant threats to social identity. Reports of slurs, offensive comments and demeaning actions spread quickly in an organization. To qualify as an event, the insult or act could not be purely interpersonal. It had to be tied to group identity in either the mind of the insulter or insultee. Sometimes the insult grew out of an ill-fated attempt at humor. These conflicts escalated quickly involving many in the organization.

In South Africa, there was a case where an administrator was accused of using a derogatory term, resulting in Africans and Afrikaners immediately taking sides. Apartheid had ended 10 years earlier, and the debate whether the administrator had used an offensive term or a similar sounding word was threatening to each of the social identity groups. There was a similar incident in the US, when an attempt at racial humor went awry and a white man ended up insulting a large number of black co-workers.

In Mozambique, a white male manager called a black receptionist an insulting name. The interviewee told us the following story:

There was a policy that denied employees to receive visits during general work hours. This policy was that we were not supposed to talk with our friends and family during work time ... and this was a policy that was supposed to be followed by everyone. And one day the wife of one of the white directors came to see him ... the receptionist said, "I'm sorry but I can't call your husband here. If you would prefer I will send him a message, and he will ring you." And she said, "No I have to go to my husband now." And the receptionist said, "Look, I'm sorry. You have to understand that I'm simply complying with the policy of the organization. I'm willing to help you, and I know you and I know your husband, but policy is policy, and it has to be followed." And the lady got angry; she eventually reached for her cell phone and called her husband ... he went downstairs to the receptionist, he yelled at her calling her all kinds of names, including names like, "you stupid, ordinary black" - things like that. 
This situation escalated to a great degree and the white director was eventually asked to leave not just the company, but the country.

Simple contact was a factor in 6 percent of the events. These stories involved a mixed group in a situation where social identity relations in society at large were tense. Simply bringing together organizational members whose identity groups are involved in a highly publicized or emotional event in the society at large can result in polarization. People walk into a situation and immediately anticipate the possibility of being ostracized or mistreated. Mere contact with the other activates a feeling of threat. For example, simple contact resulted in a situation at a hospital in Jerusalem serving Israelis and Arabs following a bombing of a public Israeli facility by Arab terrorists. An Israeli nurse who worked in a maternity ward described the following:

Interviewee: . . . in room 1 there was this "clan" of Arab women giving birth. They didn't dare to leave the room the entire day. They were afraid to come out, sat still, and we didn't get near them as well. Both because they didn't call for us, but also because ... I don't know. It's hard. You do what you have to do, what's important, but no more.

Interviewer: Can you feel the tension?

Interviewee: Yes, I think you can. In the body language, in the looks, you can feel it.

These situations were rare and occurred when organizational members from social identity groups that were strongly threatened by each other in society at large were asked to be together. A high level of vigilance seems to be required to keep the threat from overwhelming the organization.

Study 1 revealed that there were common themes in the situations that activated social identity conflicts in organizations. These situations act as triggers of societal faultlines and allow social identity conflicts to erupt at work. For the first four of these themes, the agreement between raters on the presence or absence of the theme in the data was quite acceptable, 80 percent or higher. For the fifth theme, simple contact, the agreement was 50 percent. This may be because it is a low frequency event. It also requires that the interview transcript provide ample information about the societal conflict so data analysts can recognize the issue. Since it was a small sample, we decided to leave this theme in the coding scheme even though inter-rater agreement was low. Each of the themes describes the situations that activate societal faultlines in organizations by raising the specter of threat to a particular social identity group. 


\section{Study 2}

The purpose of this study was to see how well the typology of triggers developed in Study 1 explained events identified in a larger, more varied sample. The team viewed this study as a more confirmatory approach in the elaboration of the typology, yet continued to explicitly look for additional categories that could be added or removed to refine the typology. In particular, we used the larger sample to see if events were idiosyncratic to the first sample or if there were other common triggers that failed to emerge in the first study.

\section{Sample}

Semi-structured interviews were conducted with 137 people from 13 different organizations located in nine countries. The gender distribution was approximately equal with 70 women and 67 men. Race was self-described using a variety of terms in different countries making it hard to group the different categories. Racial self-identifications included African, AfricanEuropean, African American, Arab, Asian, Black, Caucasian, Chinese, Colored, European, Indian, Various Races, White, Yellow and Does Not Apply. Table 2 contains a description of each of the 13 organizations participating in the study. Unlike the first study, where the phenomenon-focused selection process resulted in each interviewee being from a different organization, the research design for Study 2 required a minimum of 10 interviewees per organization. This change was made in an attempt to address the limitation of soliciting data from a single informant in Study 1. In addition, interviews were conducted with individuals that varied on a number of different factors (gender, race, level in the organization, etc.) in the hopes of gaining a broader understanding of how social identity-based conflict occurs in an organization. Finally, to gather more contextual information about the organization, we collected relevant documents from the organization, spoke to HR executives about corporate practices, collected survey data on the topic of diversity, and made site visits.

Because Study 2 had an increased focus on the context in which social identity-based conflict occurs, two changes were made to the sampling process to facilitate the examination of context. First, a decision was made to examine organizations in different countries, to see if similar types of triggers occurred in different cultural contexts. To maximize cultural variation in our sample, we selected countries that differed significantly in cultural values according to the dimensions developed by Hofstede (2001) and Schwartz (1992). Second, to examine the impact of context a decision was made to include both for-profit and non-profit organizations in our sample. 
Table 2. Sites in Study 2

\begin{tabular}{|c|c|c|}
\hline Site & Description & $\begin{array}{l}\text { Number } \\
\text { of events }\end{array}$ \\
\hline For-profit Brazil & $\begin{array}{l}\text { Country office of a multinational financial services } \\
\text { organization }\end{array}$ & 2 \\
\hline For-profit France & $\begin{array}{l}\text { Country office of a multinational financial services } \\
\text { organization }\end{array}$ & 4 \\
\hline For-profit Germany & $\begin{array}{l}\text { Country office of a multinational financial services } \\
\text { organization }\end{array}$ & I \\
\hline For-profit Jordan & Domestic manufacturing organization & 3 \\
\hline For-profit South Africa & Domestic financial services organization & 18 \\
\hline Non-profit Jordan & Domestic educational organization & 5 \\
\hline Non-profit South Africa & Domestic educational organization & 9 \\
\hline For-profit Singapore & $\begin{array}{l}\text { Country office of a multinational financial services } \\
\text { organization }\end{array}$ & 6 \\
\hline For profit Spain & $\begin{array}{l}\text { Country office of a multinational financial services } \\
\text { organization }\end{array}$ & 6 \\
\hline Non-profit Spain & $\begin{array}{l}\text { Regional office of a multinational human service } \\
\text { organization }\end{array}$ & 17 \\
\hline For-profit US & $\begin{array}{l}\text { Country office of a multinational financial services } \\
\text { organization }\end{array}$ & 4 \\
\hline Non-profit US & Domestic financial services organization & 21 \\
\hline For-profit Hong Kong & $\begin{array}{l}\text { Country office of a multinational financial services } \\
\text { organization }\end{array}$ & 3 \\
\hline
\end{tabular}

Total number of events analyzed $=99$.

This change was made based on the belief that the mission of the organization may play an important role in shaping what activates a faultline and whether a triggering event results in a learning opportunity or large-scale conflict within the organization. The for-profit organizations included in our sample were from Brazil, France, Germany, Hong Kong, Jordan, South Africa, Singapore, Spain and the US. The non-profit organizations included in our sample were from Jordan, South Africa, Spain and the US. 


\section{Data collection}

As with Study 1, interviewees were asked to tell a story about a conflict at work that was based on social identity, and interviewers probed to elicit additional information regarding circumstances leading up to and following the event. All interviewers were trained by the authorship team to conduct interviews on such a sensitive topic and again were provided with an interview guide. Each site had a lead investigator who was either a native of the country or educated in the country. Each investigator spent considerable time getting permission to enter the organization and collect the data. In all cases we provided some type of aggregate information back to the organization as a form of reciprocation for providing the data. The feedback did not focus on these interviews but rather shared findings from a more general survey on diversity practices that was administered to a sample of employees in each organization. We took care to protect the confidentiality of all interviewees and no examples from the interviews were used in the feedback. All interviews were recorded with permission, and interviews conducted in a language other than English were translated into English for the data analysis.

\section{Data analysis}

As the data from each site were collected, each interview was read and summarized. These summaries were thorough and focused on the entire interview. The summaries were reviewed for the purposes of identifying interviews with triggering events. Similar to Study 1, an event qualified as a trigger if 1 ) the event involved a social identity type of conflict, 2) the event was described as having some negative impact on the flow of work or other work outcomes, and 3) the interviewee provided adequate detail for analysis. Under these conditions, we were able to identify 99 stories about triggering events. Interviews that did not have a triggering event were removed from the sample. Each interview was read by two data analysts, who then constructed a summary containing the essential facts and relevant contextual information surrounding the event. The two analysts excerpted the text from the interview that dealt with the trigger.

After reading the interviews multiple times, the two analysts met to discuss the typology developed in Study 1 and to consider any events that were not adequately covered by the existing framework. Both felt the existing typology captured the bulk of the triggers that had been reviewed, but some minor elaborations were required to capture some nuances present in the larger sample. First, the larger sample of events included women reporting that the organization was unwilling to accommodate 
issues relating to pregnancy or childcare. The women felt that their distinctiveness somehow threatened the work group as a whole, and that as a result, co-workers resented this "special treatment." The assimilation category was adjusted to capture this type of event. In addition, the insult/humiliating action category was expanded to include sexual harassment and exclusion of members of a particular social identity group from events at work. Social exclusion on the basis of identity was particularly strong in the data from South Africa. Sexually harassing comments and behaviors were described as demeaning and devaluing. Finally, the Simple Contact category was modified to reinforce the impact of societal spillover within the organization.

Once the codebook was updated, each analyst independently coded each event on the basis of the excerpted text. Then the analysts met to discuss and determine a joint code, checking their codes against the revised codebook to ensure consistency. After consensus was reached for each code, the revised codebook was given to a second team of three coders. This second group was asked to code all of the excerpts independently of the first group, in order to calculate a measure of inter-rater agreement.

In Table 3, the level of agreement on the presence or absence of each code is reported. One of the five codes, Simple Contact, had a low level of agreement, 50 percent. Similar to Study 1, this may be because it is a relatively rare event, or because the language in the codebook made a reference to extreme societal conditions as a precursor to these events (e.g. a terrorist bombing resulting in high intergroup tensions). As a result, it was difficult for different coders to agree on the presence or absence of this code. As a final step, the two teams of coders met to discuss and reconcile discrepancies in order to obtain the final codes. For the four other codes, there were high levels of agreement between the two teams of coders ranging from 97 to 100 percent.

\section{Results}

Table 3 shows the degree to which each theme was present in the data. Similar to the findings in Study 1, differential treatment is the type of trigger that occurs most often. This is not all that surprising as differential treatment refers to basic in-group favoritism and out-group derogation. Varying from Study 1, assimilation has the next highest frequency, followed by insult/humiliation, and different values. Simple contact remained a relatively rare event.

Table 4 provides a visual summary of the number of triggers that were identified. Results are divided by the type of trigger and organized by country in the interest of being comprehensive, but care should be taken 
Table 3. Triggers of social identity conflicts: Study 2

\begin{tabular}{|c|c|c|c|}
\hline & Examples in Study 2 & $\begin{array}{l}\text { sample } \\
\text { strating } \\
\text { theme }\end{array}$ & $\begin{array}{l}\% \text { of rater } \\
\text { agreement }\end{array}$ \\
\hline $\begin{array}{l}\text { Differential } \\
\text { treatment }\end{array}$ & $\begin{array}{l}\text { Jordan:A Palestinian boss gave overtime pay to a } \\
\text { Palestinian and denied it to a Jordanian. } \\
\text { Singapore:There is a preference for Chinese } \\
\text { workers from China in the promotion process. } \\
\text { Chinese workers from Singapore feel unfairly treated. } \\
\text { US:An insurance benefit was perceived to favor } \\
\text { married workers over workers in domestic } \\
\text { partnerships. The gay community in the office was } \\
\text { deeply offended by the difference in benefits. }\end{array}$ & $38 \%$ & $97 \%$ \\
\hline $\begin{array}{l}\text { Different } \\
\text { values }\end{array}$ & $\begin{array}{l}\text { South Africa: Employees from different ethnic groups } \\
\text { had decidedly different values about the interaction } \\
\text { between work and personal commitments. One } \\
\text { group continually adjusted work to satisfy outside } \\
\text { commitments and the other group thought this wrong. } \\
\text { Problems about the impact of non-work activities on } \\
\text { work were brought to management. } \\
\text { Spain:A worker refused to work with a bigamous } \\
\text { colleague from Africa. He could not accept having a } \\
\text { business relationship with such a person. }\end{array}$ & $4 \%$ & $100 \%$ \\
\hline Assimilation & $\begin{array}{l}\text { Singapore:An offsite meeting was scheduled during } \\
\text { a religious holiday. Those observing the holiday felt } \\
\text { the organization discouraged their participation in a } \\
\text { religious event. } \\
\text { Spain:At a meeting one speaker insisted on speaking } \\
\text { in Catalan rather than Spanish. Others were annoyed. }\end{array}$ & $32 \%$ & $100 \%$ \\
\hline $\begin{array}{l}\text { Insult or } \\
\text { humiliating }\end{array}$ & $\begin{array}{l}\text { South Africa: Afrikaans employees accused African } \\
\text { employees of stealing milk and sugar.The accusation } \\
\text { action was later found to be false. } \\
\text { Singapore:A group of Singaporean workers spoke in } \\
\text { derogatory terms about the government of } \\
\text { Malaysia forgetting that there was a Malaysian in } \\
\text { the group. } \\
\text { Brazil:Women were offended because male } \\
\text { colleagues watched pornography at work. }\end{array}$ & $21 \%$ & $97 \%$ \\
\hline $\begin{array}{l}\text { Simple } \\
\text { contact }\end{array}$ & $\begin{array}{l}\text { Jordan: Following a local bombing of a church, } \\
\text { Christian and Muslim workers argued. }\end{array}$ & $4 \%$ & $50 \%$ \\
\hline
\end{tabular}


Table 4. Type of events by country

\begin{tabular}{|c|c|c|c|c|c|c|}
\hline Country & $\begin{array}{l}\text { Differential } \\
\text { treatment }\end{array}$ & $\begin{array}{l}\text { Different } \\
\text { values }\end{array}$ & Assimilation & $\begin{array}{c}\text { Insult/ } \\
\text { humiliating act }\end{array}$ & $\begin{array}{l}\text { Simple } \\
\text { contact }\end{array}$ & $\begin{array}{c}\text { Country } \\
\text { total }\end{array}$ \\
\hline Brazil & & & I & I & & 2 \\
\hline France & 3 & & & I & & 4 \\
\hline Germany & & & I & & & I \\
\hline Hong Kong & 1 & 1 & I & & & 3 \\
\hline Jordan & 7 & & & & I & 8 \\
\hline South Africa & 10 & 1 & I & 13 & 2 & 27 \\
\hline Singapore & 2 & & 3 & I & & 6 \\
\hline Spain & 3 & 2 & 13 & 5 & & 23 \\
\hline US & 12 & & 12 & & 1 & 25 \\
\hline Total of event type & pe 38 & 4 & 32 & 21 & 4 & 99 \\
\hline
\end{tabular}

not to interpret this as a relative ranking across countries given both the limited number of interviews and the fact that there were different numbers of usable interviews at different locations.

Differences among cultural contexts also came through in the interviewing process. Overall, cultures varied in their ability or willingness to talk about the dynamic of social identity-based conflict. In general, cultures with significant cultural heterogeneity were able to recognize and discuss the phenomenon more easily than cultures that are more homogenous. However, the organizational context played a more proximal role than culture. For example, non-profit organizations often discussed the issue of conflict with greater ease than for-profit organizations, due in part to the fact that the work of the non-profit organizations often related to issues of social justice and equality. Finally, the role of the legal system or historical context played a significant role, since the legal threat surrounding certain kinds of social-identity conflict was very salient in certain cultures (e.g. US laws regarding racial or gender discrimination).

The overall analysis, based on both Study 1 and 2, suggests that the typology provides reasonable coverage of the types of situations that activate social-identity based faultlines in organizations. The second set of data did not introduce any new categories into the classification of triggers. Since simple contact had a low level of agreement in both studies, it appears to only be useful when there is an extremely high level of societal conflict between social-identity groups. The other four types of triggers provide a broader contribution to our understanding of what activates societal faultlines in an organization. These situations trigger feelings of identity threat, 
as employees sense a possibility for harm in the workplace. Such feelings of perceived vulnerability can severely disrupt the life of an organization as employees deal with significant emotions surrounding the conflict and engage in self-protective actions.

\section{Discussion}

\section{Summary of results}

Based on the results of a combined dataset involving 134 interviews containing events from 16 different countries, we were able to address our two research questions by developing a typology of triggers that activate faultlines and cause groups to polarize at work, and identifying the most frequently observed triggers across a broad range of cultural contexts. The current study extends the social identity and faultlines literature in several ways. First, we found evidence in organizational settings to support the notion that there are many sources of faultlines, including nationality, religion, race, gender, and sexual orientation. Additionally, our findings suggest that intergroup dynamics are very much influenced by issues and events happening in society as well as deep-rooted historical tensions between social identity groups. Our data supports Lau and Murnighan's (1998) model that proposes that demographic faultlines lead to interpersonal conflicts as members break into subgroups. We also found evidence to support the fact that when tensions spill over from society to the workplace causing faultlines to crack open, the ensuing conflict can escalate to the point that it creates a challenge for organizational leaders and impacts work performance. Therefore, our findings support the assertion made by Polzer et al. (2006) who suggest that the activation of a faultline depends on whether features of the context in which a group operates highlight the faultline. Finally, our results also suggest that faultlines are primed in similar ways across many country and organizational contexts.

\section{Strengths and limitations}

The current study has several strengths, including the fact that this seems to be one of the first studies to collect data on faultlines using a large field dataset rather than conducting research in a laboratory with artificial identity groups. The study used a semi-structured interview to gather qualitative data from 134 hour-long interviews involving two separate studies in which subjects were able to provide vivid details about conflict events in the workplace. This allowed the research team to develop a typology 
based on rich data containing important information about contextual variables often ignored in previous research. The collection of interview data from multiple organizations based in different countries and in some cases, from multiple identity group perspectives, is also a strength of the present study. This diverse sample allows us to feel confident that the typology we developed is applicable across a variety of cultures and types of organizations. It also allowed us the rare opportunity to learn about triggers in different country contexts in which societal tensions and salient social identity groups vary.

Although collecting data from multiple countries is indeed one of the study's strengths, it may also be considered a weakness. The research team relied on in-country investigators to conduct many interviews and found that there was a good deal of variability in the skill of interviewers across the two samples. Some interviewers used excellent probing techniques to solicit details, while others probed very little. Some interviews had to be deleted because so few details were provided. Additionally, because different interviewers participated in different countries, it is impossible for us to conclude whether differences found across countries are due to interviewer differences or cultural differences. Another limitation is that the stories told were "in the eye of the beholder." We asked interviewees to tell us their version of the story, what they had heard, observed, or felt. In Study 2 , we had hoped that by interviewing 10 people from each organization, we would get multiple accounts of the same events and therefore be able to aggregate this qualitative data and form a collective perception of a particular event. In analyzing the data we discovered that this happened in some data sites but not others. Therefore, we decided to keep each account as a separate unit in the database because people told the stories from different vantage points. Additionally, after preliminary analysis of the data we concluded that analyzing each account separately would not impact our findings in any significant way.

\section{Future research}

Although our research was conducted in a diverse set of organizations located in multiple countries, our primary goal was understanding the phenomenon of triggers and developing a rich descriptive typology of triggers. Future research would benefit from testing this typology using a more rigorous confirmatory approach to parse out the relative impact of organizational versus cultural context variables on triggers. Such a study would require careful sampling and controls, resulting in the ability to make more generalizable comparisons across a range of different contexts. It would also 
be interesting to more thoroughly examine participant reactions to different types of triggers in future research. For example, it may be that employees respond more intensely and cope differently when responding to an insult than differential treatment, particularly in certain cultural contexts.

Research is also needed to examine the relative impact of distal and proximal contextual factors on the frequency and intensity of triggers. Research in the cross-cultural field has shown that cultural dimensions matter (Fischer, 2000; Kirkman et al., 2006), but few have examined the relative impact that a distal factor (e.g. societal or organizational culture) has compared with a more proximal contextual factor (e.g. relationships with leaders, peers, and subordinates). Several of these distal and proximal factors are conceptualized at different levels of analysis, making their identification and analysis challenging. However, management research is becoming increasingly aware of the impact that levels of analysis can have on our understanding of organizational phenomena, and the faultlines model is an area that would benefit greatly from a deeper understanding of both distal and proximal contextual factors (Yammarino et al., 2005).

Future research should also attempt to understand types of leader responses to triggers and begin to identify effective versus ineffective leader behaviors. It is likely that some leader behaviors will serve to calm tempers and de-escalate the conflict, while other leader behaviors may exacerbate the problem (intensify the cracks between subgroup boundaries) and cause the conflict to escalate further. It will be important for future researchers to begin to identify and define helpful versus harmful leader behaviors in the context of faultlines and triggers, and begin to examine leadership approaches or strategies for preventing triggers from taking place at all in the workplace. Further, research is needed to examine potential positive outcomes that may stem from conflict, such as individual or organizational learning and transformation.

\section{Implications for leaders}

When a social identity divide becomes apparent within an organization, people often look to leaders to bridge the gap. Findings from our study have implications for leaders in resolving intergroup conflict, and perhaps even more importantly, in seeking to prevent its onset. Given that differential treatment was the most frequently cited trigger in our data, this finding suggests that leaders should pay particular attention to issues of justice and fairness in the workplace. In situations where social identity groups are in conflict and emotions run high, research suggests that followers carefully consider the structures and processes leaders use to make workplace de- 
cisions (e.g. staffing, promotions, etc.) to determine if members of their social identity group or they themselves were treated fairly (De Cremer \& Tyler, 2007; Tyler \& De Cremer, 2005). Therefore, it is important that leaders employ processes perceived as fair both when making organizational decisions and when resolving social identity conflicts that follow a trigger.

For example, we heard from interviewees that it was particularly important that leaders get both sides of the story before making decisions. For the second study, we interviewed 10 or more individuals from diverse social identity groups within a single organization. Consequently, in situations where stories were repeated, we heard widely diverging interpretations of triggering events depending upon the identity of the storyteller. That is, dominant and non-dominant groups tended to hold different perceptions and make different attributions concerning the same event.

Beyond attempting to resolve social identity conflict reactively, it is important that leaders also take steps to proactively decrease the prevalence of triggering events outright. In reviewing the literature on intergroup conflict, workplace diversity, and social identity theory, Chrobot-Mason et al. (2007) previously identified four strategies leaders can use to bridge social identity group differences. These strategies include: decategorization (Brewer \& Miller, 1984; Scandura \& Lankau, 1996), in which interactions between social groups are designed to be person-based rather than identity groupbased; recategorization (Gaertner \& Dovidio, 2000; Gaertner et al., 1993), involving the creation of a common or superordinate category that is inclusive across social groups; subcategorization (Dovidio et al., 1998; Haslam \& Ellemers, 2005; Hewstone \& Brown, 1986) where interactions are structured so that identity groups have distinct but complementary roles that contribute to a common goal; and cross-cutting (Bettencourt \& Dorr, 1998; Brewer, $1995)$ that seeks to randomly or systematically cross work group roles with social group membership.

Leaders can incorporate each of the above tactics into the course of their ongoing work with functional units, project groups, task forces, or virtual teams (Ernst \& Yip, in press). Policies and practices based on these tactics can be established to bridge differences and strengthen the quality of intergroup relations on a daily basis.

As tensions and current events in the broader society spill over into organizational settings, leaders will increasingly find themselves leading on unstable ground. They will be faced with the challenge of attempting to achieve direction, alignment, and commitment in an environment where subgroup polarization and conflict is likely to ensue. Therefore, it is important that leaders detect and understand the events that activate faultlines so that they may prevent or reduce conflict and achieve positive leader- 
ship outcomes. When intergroup differences are successfully bridged, opportunities for both change and learning can occur. New knowledge in this area will help leaders not only to resolve issues of difference, but to use differences to help transform long-standing biases and beliefs in service of broader organizational goals.

\section{Acknowledgment}

The authors wish to thank their many colleagues and friends who collaborated with them on a larger project known as "Leadership Across Differences" and supported by the Center for Creative Leadership (please see http://www.ccl.org/lad for a list of team members). The authors also wish to thank two anonymous reviewers and Professor Gail Fairhurst, Associate Editor, Human Relations, for their helpful suggestions on earlier versions of the article.

\section{References}

Ashforth, B. E., \& Mael, F. A. Social identity theory and the organization. Academy of Management Review, 1989, 14, 20-39.

Bettencourt, A., \& Dorr, N. Cooperative interaction and intergroup bias: Effects of numerical representation and cross-cut role assignment. Personality and Social Psychology Bulletin, 1998, 24, 1276-93.

Boyatzis, R. E. Transforming qualitative information: Thematic analysis and code development. Thousand Oaks, CA: SAGE, 1998.

Brewer, M. Managing diversity: The role of social identities. In S. Jackson \& M. Ruderman (eds.), Diversity in work teams. Washington, DC: American Psychological Association, 1995, pp. 47-68.

Brewer, M., \& Miller, N. Beyond the contact hypothesis: Theoretical perspectives on desegregation. In N. Miller \& M. Brewer (eds.), Groups in contact: The psychology of desegregation. New York: Academic Press, 1984, pp. 49-65.

Butterfield, L. D., Borgen, W. A., Amundson, N. E., \& Maglio, A. Fifty years of the critical incident technique: 1954-3004 and beyond. Qualitative Research, 2005, 5, 475-97.

Cavey, V. Fighting among friends: The Quaker separation of 1827. In P. G. Coy \& L. M. Woehrle (eds.), Social conflicts and collective identities. Boston, MA: Rowman \& Littlefield, 2000, pp. 133-48.

Cheryan, S., \& Monin, B. "Where are you really from?": Asian Americans and identity denial. Journal of Personality and Social Psychology, 2005, 89, 717-30.

Chrobot-Mason, D., Ruderman, M. N., Weber, T. J., Ohlott, P. J., \& Dalton, M. A. Illuminating a cross-cultural leadership challenge: When identity groups collide. The International Journal of Human Resource Management, 2007, 18, 2011-36.

Crisp, R. J., \& Hewstone, M. Multiple social categorization. Advances in Experimental Social Psychology, 2007, 39, 163-254.

De Cremer, D., \& Tyler, T. The effects of trust in authority and procedural fairness on cooperation. Journal of Applied Psychology, 2007, 92, 639-49.

Dovidio, J. F., Gaertner, S. L., \& Validzic, A. Intergroup bias: Status, differentiation, and a common in-group identity. Journal of Personality and Social Psychology, 1998, 75, 109-20. 
Drath, W. H., McCauley, C. D., Palus, C. J., Van Velsor, E., O'Connor, P. M. G., \& McGuire, J. B. Direction, alignment, commitment: Toward a more integrative ontology of leadership. The Leadership Quarterly, 2008, 19, 635-53.

Ellemers, N., Spears, R., \& Doosje, B. Social identity: Context, commitment, content. Oxford: Blackwell Science, 1999.

Ernst, C., \& Yip, J. Boundary spanning leadership: Tactics to bridge social identity groups in organizations. In T. L. Pittinsky (ed.), Crossing the divide: Intergroup leadership in a world of difference. Boston, MA: Harvard Business School Press, in press.

Fisher, R. J. Intergroup conflict. In M. Deutsch, P. T. Coleman, \& E. C. Marcus (eds.), The handbook of conflict resolution: Theory and practice, 2nd ed. San Francisco, CA: Jossey-Bass, 2000, pp. 176-96.

Flanagan, J. C. The critical incident technique. Psychological Bulletin, 1954, 51, 327-58.

Gaertner, S. L., \& Dovidio, J. F. Reducing intergroup bias: The common ingroup identity model. Ann Arbor, MI: Sheridan Books, 2000.

Gaertner, S., Dovidio, J., Anastasia, P., Bachman, B., \& Rust, M. The common intergroup identity model: Recategorization and the reduction of intergroup bias. In W. Stroebe \& M. Hewstone (eds.), European review of social psychology (Vol. 4). Chichester: Wiley, 1993, pp. 1-26.

Gentry, W., Hannum, K., Munusamy, V., \& Weber, T. Managing identity conflicts: Perspectives across organisational level and culture. Social Identity Conflicts in Organisational and Cultural Context: Triggers, Responses and leadership Practices Symposium at the Internal Academy for Intercultural Research 2007, Groningen, The Netherlands, 9-12 July.

Haslam, S. A. Psychology in organizations: The social identity approach. London: SAGE, 2001.

Haslam, S. A., \& Ellemers, N. Social Identity in industrial and organizational psychology: Concepts, controversies, and contributions. In G. Hodgskinson \& J. Ford (eds.), International review of industrial and organizational psychology, Vol. 20. Chichester: Wiley, 2005, pp. 39-118.

Hewstone, M., \& Brown, R. Contact is not enough: An intergroup perspective on the contact hypothesis. In M. Hewstone \& R. Brown (eds.), Contact and conflict in intergroup encounters. Oxford: Blackwell, 1986, pp. 1-44.

Hicks, T. Another look at identity-based conflict: The roots of conflict in the psychology of consciousness. Negotiation Journal, 17, 2001, 35-45.

Hofstede, G. H. Culture's consequences: Comparing values, behaviors, institutions, and organizations across nations, 2nd ed. Thousand Oaks, CA: SAGE, 2001.

Hogg, M. A. A social identity theory of leadership. Personality and Social Psychology Review, 2001, 5, 184-200.

Hogg, M. A., Fielding, K. S., Johnson, D., Masser, B., Russell, E., \& Svensson, A. Demographic category membership and leadership in small groups: A social identity analysis. Leadership Quarterly, 2006, 17, 335-50.

Jackson, C. C., \& Neville, H. A. Influence of racial identity attitudes on African American college students' vocational identity and hope. Journal of Vocational Behavior, 1998, 53, 97-113.

Kirkman, B. L., Lowe, K. B., \& Gibson, C. B. A quarter century of Culture's Consequences: A review of empirical research incorporating Hofstede's cultural values framework. Journal of International Business Studies, 2006, 37, 285-320.

Lau, D. C., \& Murnighan, J. K. Demographic diversity and faultlines: The compositional dynamics of organizational groups. Academy of Management Review, 1998, 23, 325-40.

Lau, D. C., \& Murnighan, J. K. Interactions within groups and subgroups: The effects of demographic faultlines. Academy of Management Journal, 2005, 48, 645-59. 
Li, J. T., \& Hambrick, D. C. Factional groups: A new vantage on demographic faultlines, conflict and disintegration in work teams. Academy of Management Journal, 2005, 48, 794-813.

Linnehan, F., Chrobot-Mason, D., \& Konrad, A. M. Diversity attitudes and norms: The role of ethnic identity and relational demography. Journal of Organizational Behavior, 2006, $27,419-42$.

Molleman, E. Diversity in demographic characteristics, abilities and personality traits: Do faultlines affect team functioning? Group Decision and Negotiation, 2005, 14, 173-93.

Murphy, M. C., Steele, C. M., \& Gross, J. J. Signaling threat: How situational cues affect women in math, science, and engineering settings. Psychological Science, 2007, 18, 879-85.

Northrup, T. A. The dynamic of identity in personal and social conflict. In L. Kriesberg, T. A. Northrop, \& S. J. Thorson (eds.), Intractable conflicts and their transformation. Syracuse, NY: Syracuse University Press, 1989, pp. 55-82.

Pelham, B. W., \& Hetts, J. J. Implicit and explicit personal and social identity: Toward a more complete understanding of the social self. In T. R. Tyler, R. M. Kramer, \& O. P. John (eds.), The psychology of the social self. Mahwah, NJ: Lawrence Erlbaum Associates, 1999, pp. 115-43.

Polzer, J. T, Crisp, C. B., Jarvenpaa, S. L., \& Kim, J. W. Extending the faultline model to geographically dispersed teams: How collocated subgroups can impair group functioning. Academy of Management Journal, 2006, 49, 679-92.

Putnam, L., \& Wondolleck, J. Intractability: Definitions, dimensions, and distinctions. In R. Lewicki, B. Gray, \& M. Elliot (eds.) Making sense of intractable environmental conflicts. Washington, DC: Island Press, 2003, pp. 35-59.

Rico, R., Molleman, E., Sanchez-Manzanares, M., \& Van der Vegt, G. S. The effects of diversity faultlines and team task autonomy on decision quality and social integration. Journal of Management, 2007, 33, 111-32.

Rothman, J. Resolving identity-based conflict in nations, organizations, and communities. San Francisco, CA: Jossey-Bass, 1997.

Scandura, T., \& Lankau, M. Developing diverse leaders: A leader-member exchange approach. Leadership Quarterly, 1996, 7, 243-63.

Schwartz, S. H. Universals in the content and structure of values - theoretical advances and empirical tests in 20 countries. Advances in Experimental Social Psychology, 1992, 25, 1-65.

Shelton, J. N., Richeson, J. A., \& Vorauer, J. D. Threatened identities and interethnic interactions. European Review of Social Psychology, 2006, 17, 321-58.

Simon, B., \& Klandermans, B. Politicized collective identity: A social psychological analysis. American Psychologist, 2001, 4, 319-34.

Steele, C. M., Spencer, S., \& Aronson, J. Contending with group image: The psychology of stereotype and social identity threat. In M. P. Zanna (ed.), Advances in experimental social psychology. San Diego, CA: Academic Press, 2002, pp. 379-440.

Stephan, W. G., \& Stephan, C. W. Intergroup anxiety. Journal of Social Issues, 1985, 41, 157-75.

Strauss, A., \& Corbin, J. Basics of qualitative research: Grounded theory procedures and techniques. Newbury, CA: SAGE, 1990.

Stone, E. F. Research methods in organizational behavior. Glenview, IL: Scott Foresman, 1978.

Tajfel, H. Individuals and groups in social psychology. British Journal of Social and Clinical Psychology, 1979, 18, 183-90.

Turner, J. C. The analysis of social influence. In J. C. Turner, M. A. Hogg, P. J. Oakes, S. D. Reicher, \& M. S. Wetherell (eds.), Rediscovering the social group: A self-categorization theory. Oxford: Blackwell, 1987, pp. 68-88. 
Turner, J. C., \& Giles, H. Intergroup behavior. Oxford: Blackwell, 1981.

Tyler, T. R., \& De Cremer, D. Process-based leadership: Fair procedures and reactions to organizational change. Leadership Quarterly, 2005, 16, 529-45.

Verkuyten, M. The social psychology of ethnic identity. New York: Psychology Press, 2004.

Weaver, G. R., \& Agle, B. R. Religiosity and ethical behavior in organizations: A symbolic interactionist perspective. Academy of Management Review, 2002, 27, 77-97.

Wetherell, M. Social identity and group polarization. In J. C. Turner (ed.), Rediscovering the social group: A self-categorization theory. New York: Basil Blackwell, 1987, pp. 142-70.

Yammarino, F. J., Dionne, S. D., Chun, J. U., \& Dansereau, F. Leadership and levels of analysis: A state-of-the-science review. Leadership Quarterly, 2005, 16, 879-919.

Donna Chrobot-Mason is an Associate Professor and Director of the Center for Organizational Leadership at the University of Cincinnati. Her scholarly interests reside in the areas of organizational diversity and multicultural leadership. She has published numerous articles in journals such as International Journal of Human Resource Management, Journal of Cross-Cultural Management, Journal of Organizational Behavior, Group and Organization Management, and International Journal of Conflict Management, and also serves on the editorial review board for Personnel Psychology and Journal of Management. She has collaborated with colleagues from the Center for Creative Leadership on a study of leadership across differences for nearly 10 years. Email donna.chrobot-mason@uc.edu

Marian N. Ruderman is Director, Americas and EMEA (Europe, Middle East, and Africa) Research at the Center for Creative Leadership. Her research interests include leadership development, diversity, and work-life integration. Marian has co-authored dozens of articles and book chapters on leadership. Her work has been published in Journal of Applied Psychology, Academy of Management Journal, and Training \& Development among many others. In addition, the popular press has reported widely on Marian's work in The New York Times, Chicago Tribune, Wall Street Journal, Washington Post, Fortis Tribune, and Working Women. Her books include Standing at the crossroads: Next steps for high-achieving women (coauthored with Patricia Ohlott) and Diversity in work teams: Research paradigms for a changing workplace (co-edited with Susan Jackson). She has provided advice on leadership development and human resource planning to numerous organizations.

Email ruderman@ccl.org 
Todd J.Weber is a Post-Doctoral Research Associate with the Leadership Institute at the University of Nebraska-Lincoln. His research interests include leadership and values, with a focus on the influence that values have on the development of high quality relationships between leaders and followers. He has published in Annual Review of Psychology, Journal of Vocational Behavior, and International Journal of Human Resource Management. He is currently serving on the editorial review board for the Academy of Management Review.

Email todd.weber@gmail.com

Chris Ernst is a Senior Enterprise Associate at the Center for Creative Leadership. His work focuses on leadership as it intersects with globalization, collaboration, and intergroup relations. As a researcher, he writes and presents frequently on these topics and is author (with Maxine Dalton, Jennifer Deal, and Jean Leslie) of Success for the new global manager: How to work across distance, countries and cultures (Jossey-Bass/Wiley). As a practitioner, he has served in expatriate roles in Asia and Europe, manages and leads multicultural teams, and creates and facilitates leadership experiences for organizations worldwide.

Email ernstc@ccl.org 